\title{
Model estimates of inelastic calcium-hydrogen collision data for non-LTE stellar atmospheres modeling ${ }^{\star}$ (Research Note)
}

\author{
A. K. Belyaev ${ }^{1,2}$, S. A. Yakovleva ${ }^{2}$, M. Guitou ${ }^{3}$, A. O. Mitrushchenkov ${ }^{3}$, A. Spielfiedel ${ }^{1}$, and N. Feautrier ${ }^{1}$ \\ 1 LERMA, Observatoire de Paris, Sorbonne Université, UPMC Univ. Paris 06, CNRS-UMR 8112, 92195 Meudon, France \\ e-mail: andrey.k.belyaev@gmail.com \\ 2 Department of Theoretical Physics and Astronomy, Herzen University, Moika 48, 191186 St. Petersburg, Russia \\ ${ }^{3}$ Université Paris-Est, Laboratoire Modélisation et Simulation Multi-Echelle, UMR 8208 CNRS, 5 Bd Descartes, \\ Champs-sur-Marne, 77454 Marne la Vallée, France
}

Received 27 October 2015 / Accepted 12 January 2016

\section{ABSTRACT}

\begin{abstract}
Aims. Inelastic processes in low-energy $\mathrm{Ca}+\mathrm{H}$ and $\mathrm{Ca}^{+}+\mathrm{H}^{-}$collisions are treated for the states from the ground state up to the ionic state with the aim to provide rate coefficients needed for non-LTE modeling of $\mathrm{Ca}$ in cool stellar atmospheres.

Methods. The electronic molecular structure was determined using a recently proposed model approach that is based on an asymptotic method. Nonadiabatic nuclear dynamics were treated by means of multichannel formulas, based on the Landau-Zener model for nonadiabatic transition probabilities.

Results. The cross sections and rate coefficients for inelastic processes in $\mathrm{Ca}+\mathrm{H}$ and $\mathrm{Ca}^{+}+\mathrm{H}^{-}$collisions were calculated for all transitions between 17 low-lying covalent states plus the ionic state. It is shown that the highest rate coefficient values correspond to the excitation, de-excitation, ion-pair formation, and mutual neutralization processes involving the $\mathrm{Ca}\left(4 \mathrm{~s} 5 \mathrm{~s}{ }^{1,3} \mathrm{~S}\right)$ and the ionic $\mathrm{Ca}^{+}+$ $\mathrm{H}^{-}$states. The next group with the second highest rate coefficients includes the processes involving the $\mathrm{Ca}\left(4 \mathrm{~s} 5 \mathrm{p}^{1,3} \mathrm{P}\right), \mathrm{Ca}\left(4 \mathrm{~s} 4 \mathrm{~d}{ }^{1,3} \mathrm{D}\right)$, and $\mathrm{Ca}\left(4 \mathrm{~s} 4 \mathrm{p}{ }^{1} \mathrm{P}\right)$ states. The processes from these two groups are likely to be important for non-LTE modeling.
\end{abstract}

Key words. atomic data - line: formation - stars: abundances

\section{Introduction}

Non-local thermodynamic equilibrium (non-LTE) modeling of stellar spectra is important for many fundamental problems in modern astrophysics (see, e.g., reviews Asplund 2005; Barklem 2012, and references therein). One of the important fundamental problems of interest is determining absolute and relative abundances for different chemical elements in different stars. Calcium is of particular importance (see, for example, Andretta et al. 2005; Mashonkina et al. 2007) because it is one of the best observable chemical elements in late-type stars.

For a given atomic species, non-LTE modeling requires detailed and complete information about both the radiative and inelastic collision processes. The most important collisions are those with electrons and with hydrogen atoms and negative ions, and information about these processes gives the main uncertainty for non-LTE studies (see Asplund 2005; Barklem 2012, for a review).

Significant progress has recently been achieved in detailed quantum treatments of inelastic processes in collisions of hydrogen atoms and negative ions with atoms and positive ions of different chemical elements. Accurate quantum cross sections were calculated for transitions between many low-lying atomic and ionic states for $\mathrm{Na}, \mathrm{Li}, \mathrm{Mg}, \mathrm{He}+\mathrm{H}$, as well as for $\mathrm{Na}^{+}$,

* Tables 2-11 are only available at the CDS via anonymous ftp to cdsarc.u-strasbg.fr (130.79.128.5) or via

http://cdsarc.u-strasbg.fr/viz-bin/qcat?J/A+A/587/A114
$\mathrm{Li}^{+}, \mathrm{Mg}^{+}+\mathrm{H}^{-}$collisions (Belyaev et al. 1999; Croft et al. 1999a; Belyaev \& Barklem 2003; Belyaev et al. 2010; Guitou et al. 2011; Belyaev et al. 2012; Guitou et al. 2015; Belyaev 2015). The excitation, de-excitation, ion-pair formation, and mutual neutralization processes have been studied in detail. The resulting quantum cross sections were used to compute the inelastic rate coefficients (Croft et al. 1999b; Barklem et al. 2003, 2010, 2012) and finally for non-LTE astrophysical applications (Barklem et al. 2003; Lind et al. 2009, 2011; Mashonkina 2013; Osorio et al. 2015). It has been shown that inelastic atomic collisions of the studied elements with hydrogen are important for non-LTE modeling.

On the other hand, for many chemical elements of interest, accurate complete quantum cross sections are still not available. It is now known (Barklem et al. 2011) that the so-called Drawin formula (Steenbock \& Holweger 1984; Lambert 1993), which has been widely employed for estimates of inelastic collision rate coefficients, is not reliable. Moreover, the Drawin formula is not applicable to charge transfer processes (ion-pair formation and mutual neutralization processes), which have been found to be the most important processes in the cases studied so far (e.g., Barklem et al. 2003) ${ }^{1}$.

\footnotetext{
1 The ion-pair formation (charge transfer) process is not to be confused with the ionization process. The physical mechanisms of these processes are different (transitions between stationary electronic states for charge transfer versus transitions between stationary and quasistationary states for ionization), therefore ionization process rates cannot be used as estimates for charge transfer rates.
} 
For these reasons, approximate but physically reliable approaches to inelastic atomic collisions with hydrogen atoms are highly desirable. Such model approaches have recently been proposed by Belyaev (2013a) and Belyaev et al. (2014) based on a semi-empirical asymptotic method for determining molecular potential energies, on the branching-probability-current method, and on the analytic multichannel formulas for the nonadiabatic nuclear dynamics. The approaches have been applied to $\mathrm{Al}+\mathrm{H}$ (Belyaev 2013b) and $\mathrm{Si}+\mathrm{H}$ (Belyaev et al. 2014) collisions. The main goal of these approaches is to calculate inelastic rate coefficients with high values and estimate rate coefficients with moderate values, that is, rates of probable astrophysical interest.

In the present paper, the model multichannel approach (Belyaev et al. 2014) is applied to low-energy inelastic $\mathrm{Ca}+\mathrm{H}$ and $\mathrm{Ca}^{+}+\mathrm{H}^{-}$collisions, which are of interest for stellar spectrum modeling. Since the treated inelastic processes are determined by nonadiabatic transitions, which are quantum by nature, the model approach is essentially quantum as well.

\section{Model approach}

The present study was performed within the standard BornOppenheimer formalism, which is the most widely used and reliable approach for theoretical studies of low-energy heavyparticle collisions. The approach treats a collision problem in two steps: electronic structure calculations and nonadiabatic nuclear dynamics. Although there are some ab initio data for the $\mathrm{CaH}\left({ }^{2} \Sigma^{+}\right)$adiabatic potential energy curves (Chambaud \& Lévy 1989; Boutalib et al. 1992, see also references therein), the number of states treated is small, the internuclear distance grid is rather sparse, and there is no information about nonadiabatic coupling matrix elements. All this prevents performing a detailed, full quantum treatment of low-energy inelastic $\mathrm{Ca}+\mathrm{H}$ collision processes. Electronic structure information (Chambaud \& Lévy 1989; Boutalib et al. 1992) is not sufficient even for using model approaches. For this reason, the adiabatic potentials are estimated in the present work by means of the asymptotic model (Belyaev 2013a). New accurate ab initio electronic structure calculations are highly desirable.

Our experience of the previous similar studies shows that rate coefficients with high and moderate values are determined by the long-range ionic-covalent interaction. In the present case, the ionic molecular state has a ${ }^{2} \Sigma^{+}$symmetry, therefore it is sufficient to treat nonadiabatic transitions within this molecular symmetry alone. The model was adapted to the case of the molecular states built from doubly excited calcium configurations. The corresponding long-range molecular $\mathrm{CaH}\left({ }^{2} \Sigma^{+}\right)$adiabatic potential energies calculated by the asymptotic model approach (Belyaev 2013a) are plotted in Fig. 1 for the internuclear distances $>10$ atomic units and compared with the available ab initio data (Chambaud \& Lévy 1989; Boutalib et al. 1992). The molecular states used are collected in Table 1.

The nonadiabatic transition probabilities can be obtained within the Landau-Zener model, and the Landau-Zener parameters can be calculated by means of the so-called adiabaticpotential-based formula (Belyaev \& Lebedev 2011; Belyaev 2013a), which only requires information about the adiabatic splittings. Figure 1 shows that the adiabatic splittings calculated by means of the asymptotic model approach and the ab initio methods agree reasonably well with each other, especially for the uppermost nonadiabatic region between the 6 th $(j=6)$ and the 7th $(j=7)$ molecular states in the vicinity of the internuclear distance $R$ of 20 atomic units. The splitting between the

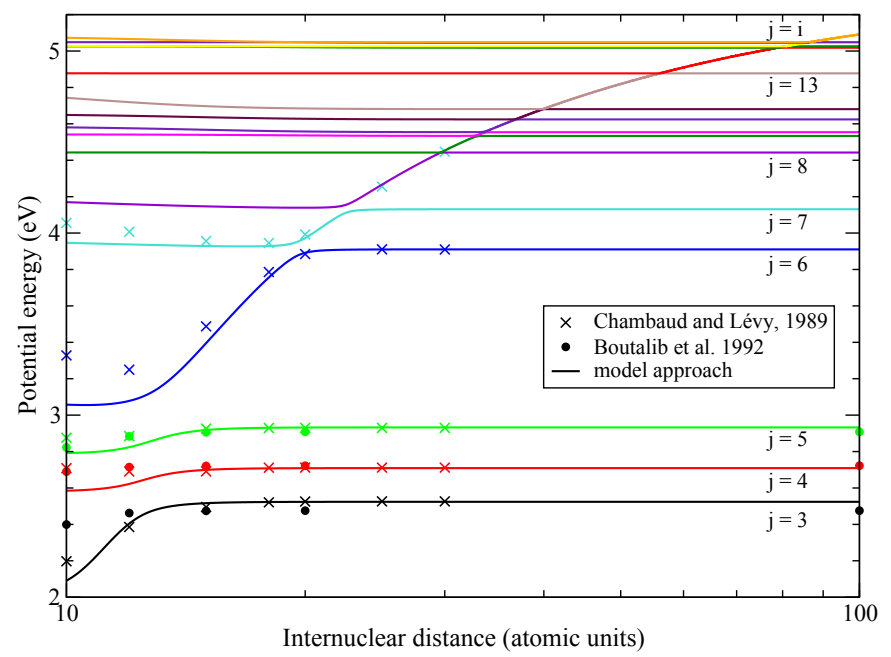

Fig. 1. $\mathrm{CaH}\left({ }^{2} \Sigma^{+}\right)$adiabatic potential energy curves obtained by means of the present model approach (solid lines) and by the ab initio calculations (Chambaud \& Lévy 1989; Boutalib et al. 1992) (symbols). The potentials are measured from the ground state asymptote. The potential labels are defined in Table 1.

Table 1. $\mathrm{CaH}\left({ }^{2} \Sigma^{+}\right)$molecular channels and asymptotic energies $(J$-average experimental values taken from NIST Kramida et al. 2012) with respect to the ground state.

\begin{tabular}{|c|c|c|}
\hline$j$ & $\begin{array}{l}\text { Asymptotic } \\
\text { atomic states }\end{array}$ & $\begin{array}{c}\text { Asymptotic } \\
\text { energies }(\mathrm{eV})\end{array}$ \\
\hline 1 & $\mathrm{Ca}\left(4 \mathrm{~s}^{2}{ }^{1} \mathrm{~S}\right)+\mathrm{H}\left(1 \mathrm{~s}^{2} \mathrm{~S}\right)$ & 0.0 \\
\hline 2 & $\mathrm{Ca}\left(4 \mathrm{~s} 4 \mathrm{p}^{3} \mathrm{P}\right)+\mathrm{H}\left(1 \mathrm{~s}^{2} \mathrm{~S}\right)$ & 1.892 \\
\hline 3 & $\mathrm{Ca}\left(3 \mathrm{~d} 4 \mathrm{~s}^{3} \mathrm{D}\right)+\mathrm{H}\left(1 \mathrm{~s}^{2} \mathrm{~S}\right)$ & 2.524 \\
\hline 4 & $\mathrm{Ca}\left(3 \mathrm{~d} 4 \mathrm{~s}{ }^{1} \mathrm{D}\right)+\mathrm{H}\left(1 \mathrm{~s}^{2} \mathrm{~S}\right)$ & 2.709 \\
\hline 5 & $\mathrm{Ca}\left(4 \mathrm{~s} 4 \mathrm{p}^{1} \mathrm{P}\right)+\mathrm{H}\left(1 \mathrm{~s}^{2} \mathrm{~S}\right)$ & 2.933 \\
\hline 6 & $\mathrm{Ca}\left(4 \mathrm{~s} 5 \mathrm{~s}^{3} \mathrm{~S}\right)+\mathrm{H}\left(1 \mathrm{~s}^{2} \mathrm{~S}\right)$ & 3.910 \\
\hline 7 & $\mathrm{Ca}\left(4 \mathrm{~s} 5 \mathrm{~s}^{1} \mathrm{~S}\right)+\mathrm{H}\left(1 \mathrm{~s}^{2} \mathrm{~S}\right)$ & 4.131 \\
\hline 8 & $\mathrm{Ca}\left(3 \mathrm{~d} 4 \mathrm{p}^{3} \mathrm{~F}\right)+\mathrm{H}\left(1 \mathrm{~s}^{2} \mathrm{~S}\right)$ & 4.442 \\
\hline 9 & $\mathrm{Ca}\left(4 \mathrm{~s} 5 \mathrm{p}{ }^{3} \mathrm{P}\right)+\mathrm{H}\left(1 \mathrm{~s}^{2} \mathrm{~S}\right)$ & 4.534 \\
\hline 10 & $\mathrm{Ca}\left(4 \mathrm{~s} 5 \mathrm{p}^{1} \mathrm{P}\right)+\mathrm{H}\left(1 \mathrm{~s}^{2} \mathrm{~S}\right)$ & 4.554 \\
\hline 11 & $\mathrm{Ca}\left(4 \mathrm{~s} 4 \mathrm{~d}^{1} \mathrm{D}\right)+\mathrm{H}\left(1 \mathrm{~s}^{2} \mathrm{~S}\right)$ & 4.624 \\
\hline 12 & $\mathrm{Ca}\left(4 \mathrm{~s} 4 \mathrm{~d}^{3} \mathrm{D}\right)+\mathrm{H}\left(1 \mathrm{~s}^{2} \mathrm{~S}\right)$ & 4.681 \\
\hline 13 & $\mathrm{Ca}\left(3 \mathrm{~d} 4 \mathrm{p}^{3} \mathrm{P}\right)+\mathrm{H}\left(1 \mathrm{~s}^{2} \mathrm{~S}\right)$ & 4.877 \\
\hline 14 & $\mathrm{Ca}\left(4 \mathrm{~s} 6 \mathrm{~s}^{3} \mathrm{~S}\right)+\mathrm{H}\left(1 \mathrm{~s}^{2} \mathrm{~S}\right)$ & 5.018 \\
\hline 15 & $\mathrm{Ca}\left(3 \mathrm{~d} 4 \mathrm{p}^{1} \mathrm{~F}\right)+\mathrm{H}\left(1 \mathrm{~s}^{2} \mathrm{~S}\right)$ & 5.026 \\
\hline 16 & $\mathrm{Ca}\left(4 \mathrm{~s} 6 \mathrm{~s}{ }^{1} \mathrm{~S}\right)+\mathrm{H}\left(1 \mathrm{~s}^{2} \mathrm{~S}\right)$ & 5.045 \\
\hline 17 & $\mathrm{Ca}\left(4 \mathrm{p}^{2}{ }^{1} \mathrm{D}\right)+\mathrm{H}\left(1 \mathrm{~s}^{2} \mathrm{~S}\right)$ & 5.049 \\
\hline $\mathrm{i}$ & $\mathrm{Ca}^{+}\left(4 \mathrm{~s}^{2} \mathrm{~S}\right)+\mathrm{H}^{-}\left(1 \mathrm{~s}^{2}{ }^{1} \mathrm{~S}\right)$ & 5.363 \\
\hline
\end{tabular}

model adiabatic potentials reaches the minimum of $0.0756 \mathrm{eV}$ at $R=19.64$ atomic units, while the splitting between ab initio potentials is equal to $0.1076 \mathrm{eV}$ at $R=20$ atomic units (Chambaud \& Lévy 1989); the main difference in these splittings comes from the different internuclear distances. As shown below, this splitting determines the inelastic rate coefficient with the highest value in $\mathrm{Ca}+\mathrm{H}$ collisions, which means that the model asymptotic adiabatic potentials provide a reliable background for estimates of inelastic rate coefficients with high and moderate values.

The model asymptotic approach allows considering longrange nonadiabatic regions that are due to ionic-covalent interactions. In this case, nonadiabatic regions are passed by the system 
in a particular order, and the multichannel model (Belyaev \& Tserkovnyi 1987; Belyaev 1993; Belyaev \& Barklem 2003; Belyaev et al. 2014) can be used to treat the nonadiabatic nuclear dynamics. This model is advantageous because it is analytical. Comparison with the previous quantum calculations has shown that the model approach to nonadiabatic nuclear dynamics provides reasonable estimates for inelastic processes with high and moderate values (Belyaev et al. 2014; Guitou et al. 2015).

\section{Calculation results}

The present study of inelastic calcium-hydrogen collisions was performed for eighteen scattering channels that give the $\mathrm{CaH}\left({ }^{2} \Sigma^{+}\right)$molecular states: the seventeen low-lying covalent states formed by the ground and the low-lying excited atomic states of calcium interacting with a ground-state hydrogen atom, as well as an ionic pair in its ground state. The molecular states treated are listed in Table 1. Molecular states of other symmetries are not included in the present consideration. The asymptotic model adiabatic potentials are plotted in Fig. 1. Shortrange potentials estimated by the asymptotic model approach are not shown in the figure at $R<10$ atomic units, since the low-energy collision rate coefficients with high and moderate values are determined by long-range potentials. A series of avoided crossings due to the ionic-covalent interactions is clearly seen. Landau-Zener parameters in each nonadiabatic region were determined by means of the adiabatic-potential-based formula (Belyaev \& Lebedev 2011; Belyaev 2013a) followed by calculations of nonadiabatic transition probabilities by means of the multichannel formula (Belyaev et al. 2014). Inelastic cross sections and rate coefficients for all transitions between the states listed in Table 1 were then calculated as usual.

The inelastic processes in calcium-hydrogen collisions, as well as the same processes in similar collisions of other chemical elements with hydrogen (see, e.g., Belyaev et al. 2010, 2014, 2012; Belyaev 2013a), can be divided into three groups according to their values for inelastic rate coefficients. Analysis of the present calculated rate coefficients allows us to define these groups as follows. The first group consists of processes with the highest rate coefficients, typically on an order of magnitude larger than $10^{-8} \mathrm{~cm}^{3} / \mathrm{s}$. The second group includes processes with moderate values of rate coefficients, typically between $10^{-11}$ and $10^{-8} \mathrm{~cm}^{3} / \mathrm{s}$. The third group consists of processes with low rate coefficients, at present, lower than $10^{-11} \mathrm{~cm}^{3} / \mathrm{s}$. In the present case, this group includes the processes involving the two lowest atomic states (that is, the ground $\mathrm{Ca}\left(4 \mathrm{~s}^{2}{ }^{1} \mathrm{~S}\right)$ state, the channel $j=1$, and the first excited $\mathrm{Ca}\left(4 \mathrm{~s} 4 \mathrm{p}{ }^{3} \mathrm{P}\right)$ state, the channel $j=2$ ), as well as the high-lying excited states starting from the $\mathrm{Ca}\left(3 \mathrm{~d} 4 \mathrm{p}{ }^{3} \mathrm{P}\right)$ state, the channels $j \geq 13$, but ionic. Since the last group has negligibly low values for rate coefficients, this group was excluded from the presentation in this Research Note, even though these rate coefficients were calculated. The rate coefficients for other inelastic processes are presented in Table A.1. The calculated rate coefficients are available upon request and/or as a supplementary materials to this Research Note.

Table A.1 shows that the highest rate coefficient values correspond to the excitation, de-excitation, ion-pair formation, and mutual neutralization processes involving the $\mathrm{Ca}\left(4 \mathrm{~s} 5 \mathrm{~s}{ }^{1,3} \mathrm{~S}\right)$ states and the ground ionic $\mathrm{Ca}^{+}+\mathrm{H}^{-}$state (the first group). For example, the rate coefficients for the mutual neutralization processes $\mathrm{Ca}^{+}+\mathrm{H}^{-} \rightarrow \mathrm{Ca}^{*}+\mathrm{H}$ at temperature $T=6000 \mathrm{~K}$ have the highest values $4.61 \times 10^{-8} \mathrm{~cm}^{3} / \mathrm{s}$ and $5.27 \times 10^{-8} \mathrm{~cm}^{3} / \mathrm{s}$ for the final states $\mathrm{Ca}\left(4 \mathrm{~s} 5 \mathrm{~s}{ }^{3} \mathrm{~S}\right)$ and $\mathrm{Ca}\left(4 \mathrm{~s} 5 \mathrm{~s}{ }^{1} \mathrm{~S}\right)$, respectively. The de-excitation process $\mathrm{Ca}\left(4 \mathrm{~s} 5 \mathrm{~s}{ }^{1} \mathrm{~S}\right)+\mathrm{H} \rightarrow \mathrm{Ca}\left(4 \mathrm{~s} 5 \mathrm{~s}{ }^{3} \mathrm{~S}\right)+\mathrm{H}$ at

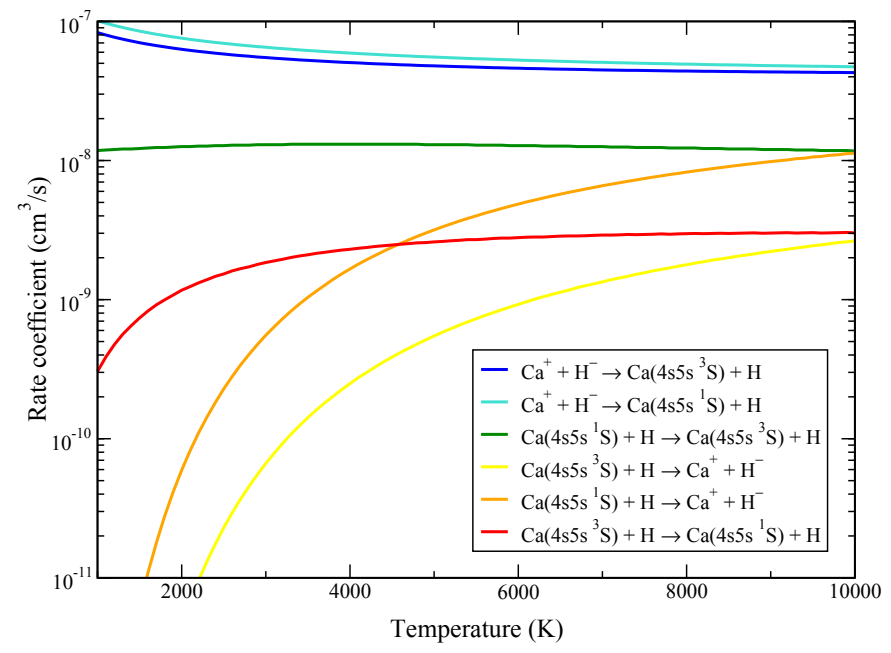

Fig. 2. Temperature dependence of rate coefficients for the inelastic processes in calcium-hydrogen collisions with the highest values.

the same temperature has a rate coefficient of $1.28 \times 10^{-8} \mathrm{~cm}^{3} / \mathrm{s}$. The temperature dependences of the rate coefficients for the processes from the first group are plotted in Fig. 2.

The second group with the second highest rate coefficients includes the processes involving the $\mathrm{Ca}\left(4 \mathrm{~s} 5 \mathrm{p}{ }^{1,3} \mathrm{P}\right)$, $\mathrm{Ca}\left(4 \mathrm{~s} 4 \mathrm{~d}^{1,3} \mathrm{D}\right)$, and $\mathrm{Ca}\left(4 \mathrm{~s} 4 \mathrm{p}{ }^{1} \mathrm{P}\right)$ states. The rate coefficients for the mutual neutralization processes involving these states as the final states typically have the values of $10^{-9}-10^{-8} \mathrm{~cm}^{3} / \mathrm{s}$, while rate coefficients for the de-excitation (and excitation) processes are smaller by typically at least an order (or several orders) of magnitude.

We note that there are several states, $j=8,13,15,17$, which are coupled with the ground ionic state by two-electrontransition interactions. The off-diagonal matrix elements for these states are much smaller than off-diagonal matrix elements for single-electron transitions. This results in much lower values for the corresponding rate coefficients, see Table A.1.

\section{Conclusion}

Cross sections and rate coefficients for inelastic processes in $\mathrm{Ca}+\mathrm{H}$ and $\mathrm{Ca}^{+}+\mathrm{H}^{-}$collisions for all transitions between 17 low-lying covalent states plus the ionic state were calculated. It was shown that the highest rate coefficients, with values up to $5 \times 10^{-8} \mathrm{~cm}^{3} / \mathrm{s}$, correspond to the excitation, de-excitation, ion-pair formation, and mutual neutralization processes involving the $\mathrm{Ca}\left(4 \mathrm{~s} 5 \mathrm{~s}{ }^{1,3} \mathrm{~S}\right)$ and the ionic $\mathrm{Ca}^{+}+\mathrm{H}^{-}$states. The next group with the second highest rate coefficients includes the processes involving the $\mathrm{Ca}\left(4 \mathrm{~s} 5 \mathrm{p}^{1,3} \mathrm{P}\right), \mathrm{Ca}\left(4 \mathrm{~s} 4 \mathrm{~d}^{1,3} \mathrm{D}\right)$, and $\mathrm{Ca}\left(4 s 4 \mathrm{p}{ }^{1} \mathrm{P}\right)$ states. These processes from the first and second group are likely to be important for non-LTE modeling. The processes that involve the ground and first excited state of calcium, $\mathrm{Ca}\left(4 \mathrm{~s} 4 \mathrm{p}{ }^{3} \mathrm{P}\right)$, as well the high-lying states starting from the $\mathrm{Ca}\left(3 \mathrm{~d} 4 \mathrm{p}{ }^{3} \mathrm{P}\right)$ state, have negligible rate coefficients and are expected to be unimportant for astrophysical applications. The present data provide a reliable basis for non-LTE stellar atmosphere modeling of the spectrum of calcium.

Acknowledgements. A.K.B. and S.A.Y. gratefully acknowledge partial support from the Ministry for Education and Science (Russian Federation). A.K.B. also gratefully acknowledges support from the Paris Observatory and the UPMC Paris University (France). S.A.Y. also gratefully acknowledges partial support from the Dynasty Foundation (Russian Federation). 


\section{References}

Andretta, V., Busá, I., Gomez, M. T., \& Terranegra, L. 2005, A\&A, 430, 669 Asplund, M. 2005, ARA\&A, 43, 481

Barklem, P. S. 2012, J. Phys. Conf. Ser., 397, 012049

Barklem, P. S., Belyaev, A. K., \& Asplund, M. 2003, A\&A, 409, L1

Barklem, P. S., Belyaev, A. K., Dickinson, A. S., \& Gadéa, F. X. 2010, A\&A, 519, A20

Barklem, P. S., Belyaev, A. K., Guitou, M., et al. 2011, A\&A, 530, A94

Barklem, P. S., Belyaev, A. K., Spielfiedel, A., Guitou, M., \& Feautrier, N. 2012, A\&A, 541, A80

Belyaev, A. K. 1993, Phys. Rev. A, 48, 4299

Belyaev, A. K. 2013a, Phys. Rev. A, 88, 052704

Belyaev, A. K. 2013b, A\&A, 560, A60

Belyaev, A. K. 2015, Phys. Rev. A, 91, 062709

Belyaev, A. K., \& Barklem, P. S. 2003, Phys. Rev. A, 68, 062703

Belyaev, A. K., \& Lebedev, O. V. 2011, Phys. Rev. A, 84, 014701

Belyaev, A. K., \& Tserkovnyi, S. I. 1987, Opt. Spektrosk., 63, 968

Belyaev, A. K., Grosser, J., Hahne, J., \& Menzel, T. 1999, Phys. Rev. A, 60, 2151

Belyaev, A. K., Barklem, P. S., Dickinson, A. S., \& Gadéa, F. X. 2010, Phys. Rev. A, 81, 032706
Belyaev, A. K., Barklem, P., Spielfiedel, A., et al. 2012, Phys. Rev. A, 85, 032704 Belyaev, A. K., Yakovleva, S. A., \& Barklem, P. S. 2014, A\&A, 572, A103 Boutalib, A., Daudey, J., \& Mouhtadi, M. E. 1992, Chem. Phys., 167, 111

Chambaud, G., \& Lévy, B. 1989, J. Phys. B At. Mol. Opt. Phys., 22, 3155

Croft, H., Dickinson, A. S., \& Gadéa, F. X. 1999a, J. Phys. B: At. Mol. Opt. Phys., 32, 81

Croft, H., Dickinson, A. S., \& Gadéa, F. X. 1999b, MNRAS, 304, 327

Guitou, M., Belyaev, A. K., Barklem, P. S., Spielfiedel, A., \& Feautrier, N. 2011, J. Phys. B: At. Mol. Opt. Phys., 44, 035202

Guitou, M., Spielfiedel, A., Rodionov, D. S., et al. 2015, Chem. Phys., 462, 94 Kramida, A., Ralchenko, Y., Reader, J., \& NIST ASD Team 2012, in NIST Atomic Spectroscopy Database (National Institute of Standards and Technology, Gaithersburg), Version 5.0, http://physics.nist.gov/asd Lambert, D. L. 1993, Phys. Scr., T, 47, 186

Lind, K., Asplund, M., \& Barklem, P. S. 2009, A\&A, 503, 541

Lind, K., Asplund, M., Barklem, P. S., \& Belyaev, A. K. 2011, A\&A, 528, A103 Mashonkina, L. 2013, A\&A, 550, A28

Mashonkina, L., Korn, A. J., \& Przybilla, N. 2007, A\&A, 461, 261

Osorio, Y., Barklem, P. S., Lind, K., et al. 2015, A\&A, 579, A53

Steenbock, W., \& Holweger, H. 1984, A\&A, 130, 319 
A. K. Belyaev et al.: Inelastic processes in calcium-hydrogen collisions $(R N)$

\section{Appendix A: Additional table}

Table A.1. Rate coefficients, in units of $\mathrm{cm}^{3} / \mathrm{s}$, for selected temperatures in the range $T=2000-10000 \mathrm{~K}$, for the excitation, de-excitation, ion-pair formation, and mutual neutralization processes in calcium-hydrogen collisions.

\begin{tabular}{|c|c|c|c|c|c|c|c|c|c|c|c|}
\hline $\begin{array}{l}\text { Initial } \\
\text { state }\end{array}$ & 3 & 4 & 5 & 6 & 7 & $\begin{array}{c}\text { Final state } \\
8\end{array}$ & 9 & 10 & 11 & 12 & $i$ \\
\hline \multicolumn{12}{|c|}{$T=2000 \mathrm{~K}$} \\
\hline 3 & - & $4.98 \mathrm{E}-13$ & $1.67 \mathrm{E}-15$ & $6.38 \mathrm{E}-18$ & $1.51 \mathrm{E}-18$ & $3.93 \mathrm{E}-20$ & 7.09E-20 & $5.15 \mathrm{E}-20$ & $2.53 \mathrm{E}-20$ & $1.55 \mathrm{E}-20$ & $4.95 \mathrm{E}-20$ \\
\hline 4 & $4.37 \mathrm{E}-12$ & - & $1.37 \mathrm{E}-12$ & $1.93 \mathrm{E}-15$ & $3.63 \mathrm{E}-16$ & $1.08 \mathrm{E}-17$ & $1.46 \mathrm{E}-17$ & $1.03 \mathrm{E}-17$ & $5.22 \mathrm{E}-18$ & & $6.40 \mathrm{E}-18$ \\
\hline 5 & $8.94 \mathrm{E}-14$ & $8.36 \mathrm{E}-12$ & - & $6.18 \mathrm{E}-13$ & & $2.91 \mathrm{E}-15$ & & & & & \\
\hline 6 & $9.95 \mathrm{E}-14$ & $43 \mathrm{E}-12$ & $.80 \mathrm{E}-10$ & - & 1.17E-09 & $5.24 \mathrm{E}-11$ & $2.69 \mathrm{E}-11$ & $1.68 \mathrm{E}-11$ & $9.63 \mathrm{E}-12$ & $6.18 \mathrm{E}-12$ & $4.59 \mathrm{E}-12$ \\
\hline 7 & $54 \mathrm{E}-13$ & $.94 \mathrm{E}-12$ & $2.61 \mathrm{E}-10$ & $1.26 \mathrm{E}-08$ & - & $1.23 \mathrm{E}-09$ & $4.25 \mathrm{E}-10$ & $2.50 \mathrm{E}-10$ & $1.46 \mathrm{E}-10$ & $9.19 \mathrm{E}$ & 5.95E-11 \\
\hline 8 & $92 \mathrm{E}-15$ & $.03 \mathrm{E}-14$ & $2.65 \mathrm{E}-12$ & $1.64 \mathrm{E}-10$ & $3.57 \mathrm{E}-10$ & - & $3.36 \mathrm{E}-15$ & $1.64 \mathrm{E}-15$ & $8.37 \mathrm{E}$ & $4.71 \mathrm{E}-16$ & $3.03 \mathrm{E}-16$ \\
\hline 9 & $1.37 \mathrm{E}-14$ & $.21 \mathrm{E}-13$ & $9.89 \mathrm{E}-12$ & 3.33E-10 & $4.88 \mathrm{E}-10$ & $1.33 \mathrm{E}-14$ & - & $1.12 \mathrm{E}-10$ & $4.20 \mathrm{E}-11$ & $2.13 \mathrm{E}-11$ & $1.29 \mathrm{E}-11$ \\
\hline 10 & $3.36 \mathrm{E}-14$ & $.69 \mathrm{E}-13$ & $2.29 \mathrm{E}-11$ & $7.04 \mathrm{E}-10$ & $9.73 \mathrm{E}-10$ & $2.19 \mathrm{E}-14$ & $3.80 \mathrm{E}-10$ & - & $1.40 \mathrm{E}-10$ & $6.28 \mathrm{E}-11$ & $3.63 \mathrm{E}-11$ \\
\hline 11 & 49E-14 & $.50 \mathrm{E}-13$ & $1.08 \mathrm{E}-11$ & $3.64 \mathrm{E}-10$ & $5.13 \mathrm{E}-10$ & $1.01 \mathrm{E}-14$ & $1.28 \mathrm{E}-10$ & $1.26 \mathrm{E}-10$ & - & $3.91 \mathrm{E}-11$ & $1.42 \mathrm{E}-11$ \\
\hline 12 & $21 \mathrm{E}-15$ & $.00 \mathrm{E}-13$ & $3.14 \mathrm{E}-12$ & $1.08 \mathrm{E}-10$ & $1.49 \mathrm{E}-10$ & $2.63 \mathrm{E}-15$ & $3.00 \mathrm{E}-11$ & $2.62 \mathrm{E}-11$ & $1.81 \mathrm{E}-11$ & - & $2.84 \mathrm{E}-12$ \\
\hline$i$ & $06 \mathrm{E}-11$ & $1.56 \mathrm{E}-10$ & 2.92E-09 & $6.31 \mathrm{E}-08$ & $7.58 \mathrm{E}-08$ & $1.33 \mathrm{E}-12$ & $1.43 \mathrm{E}-08$ & 1.19E-08 & $5.18 \mathrm{E}-09$ & 2.23E-09 & - \\
\hline \multicolumn{12}{|c|}{$T=4000 \mathrm{~K}$} \\
\hline 3 & - & $4.15 \mathrm{E}-12$ & $5.60 \mathrm{E}-14$ & 7.77E-16 & $2.99 \mathrm{E}-16$ & $4.03 \mathrm{E}-18$ & $1.89 \mathrm{E}-17$ & $1.46 \mathrm{E}-17$ & $6.78 \mathrm{E}-18$ & 3.93E-18 & $2.10 \mathrm{E}-16$ \\
\hline 4 & $2.13 \mathrm{E}-11$ & - & $1.20 \mathrm{E}-11$ & 14 & E-14 & $6.57 \mathrm{E}-16$ & & & & & \\
\hline 5 & $16 \mathrm{E}-13$ & $3.83 \mathrm{E}-11$ & - & $1.14 \mathrm{E}-11$ & E-12 & $9.46 \mathrm{E}-14$ & $1.83 \mathrm{E}$ & 1.3 & 14 & & \\
\hline 6 & 17E-13 & $.15 \mathrm{E}-12$ & $1.94 \mathrm{E}-10$ & - & 2.30E-09 & $1.11 \mathrm{E}-10$ & $1.08 \mathrm{E}-10$ & 7.39E-11 & $4.18 \mathrm{E}$ & $2.77 \mathrm{E}$ & $2.49 \mathrm{E}-10$ \\
\hline 7 & $75 \mathrm{E}-13$ & $.01 \mathrm{E}-11$ & $3.07 \mathrm{E}-10$ & $1.31 \mathrm{E}-08$ & - & $1.45 \mathrm{E}-09$ & $9.40 \mathrm{E}-10$ & $6.10 \mathrm{E}-10$ & $3.52 \mathrm{E}-10$ & $2.30 \mathrm{E}$ & $1.66 \mathrm{E}-09$ \\
\hline 8 & $52 \mathrm{E}-16$ & .39E-14 & $1.08 \mathrm{E}-12$ & $7.45 \mathrm{E}-11$ & $.71 \mathrm{E}-10$ & - & $3.88 \mathrm{E}-15$ & $2.23 \mathrm{E}-15$ & $1.05 \mathrm{E}$ & $5.83 \mathrm{I}$ & $3.36 \mathrm{E}-15$ \\
\hline 9 & $07 \mathrm{E}-14$ & 13 & $6.35 \mathrm{E}$ & 10 & -10 & $1.18 \mathrm{E}-14$ & - & $9.61 \mathrm{E}-11$ & $3.76 \mathrm{~F}$ & & \\
\hline 10 & & & & & & $6 \mathrm{E}-14$ & 0 & - & $1.15 \mathrm{E}-$ & & \\
\hline 11 & & & & & -10 & -15 & & & - & $2.85 \mathrm{E}-11$ & \\
\hline 12 & & & & & & & & & & - & $1.59 \mathrm{E}-$ \\
\hline$i$ & & & & & E-08 & $1.02 \mathrm{E}-12$ & & & & & - \\
\hline \multicolumn{12}{|c|}{$T=6000 \mathrm{~K}$} \\
\hline 3 & - & $1.16 \mathrm{E}-11$ & $2.89 \mathrm{E}-13$ & 5.64E-15 & E-15 & $1.45 \mathrm{E}-17$ & $1.30 \mathrm{E}-16$ & $1.02 \mathrm{E}-16$ & $4.36 \mathrm{E}-17$ & $2.28 \mathrm{E}-17$ & $4.23 \mathrm{E}-15$ \\
\hline 4 & $4.97 \mathrm{E}-11$ & - & $3.40 \mathrm{E}-11$ & & E-13 & $2.00 \mathrm{E}-15$ & $1.01 \mathrm{I}$ & & & & \\
\hline 5 & 19E-12 & .74E-11 & - & $3.27 \mathrm{E}-11$ & E-11 & $4 \mathrm{E}-13$ & & & & & \\
\hline 6 & $2 \mathrm{E}-13$ & & $17 \mathrm{E}-10$ & - & 2.79E-09 & E-10 & & & & & \\
\hline 7 & & & & $28 \mathrm{E}-08$ & - & $1.21 \mathrm{E}-09$ & & & & & \\
\hline 8 & & & & & $05 \mathrm{E}-10$ & - & $3.49 \mathrm{E}-$ & & & & \\
\hline 9 & & & & & & $2 \mathrm{E}-15$ & - & 1 & & & \\
\hline 10 & & & & & & & & - & 8.98E-11 & & \\
\hline 11 & & & 2 & & & 15 & & & - & $2.09 \mathrm{E}-11$ & -10 \\
\hline 12 & & 3 & 3 & 1 & E-11 & 5 & 11 & & 2 & - & $2.73 \mathrm{E}-11$ \\
\hline$i$ & $1.54 \mathrm{E}-11$ & $1.77 \mathrm{E}-10$ & $2.63 \mathrm{E}-09$ & 4.61E-08 & $5.27 \mathrm{E}-08$ & $8.88 \mathrm{E}-13$ & $9.76 \mathrm{E}-09$ & $8.13 \mathrm{E}-09$ & $3.54 \mathrm{E}-09$ & $1.53 \mathrm{E}-09$ & - \\
\hline \multicolumn{12}{|c|}{$T=8000 \mathrm{~K}$} \\
\hline 3 & - & $2.21 \mathrm{E}-11$ & & & E-15 & $2.43 \mathrm{E}-17$ & & & & & \\
\hline 4 & $8.68 \mathrm{E}-11$ & - & $6.55 \mathrm{E}-11$ & & $4.14 \mathrm{E}-13$ & $3.05 \mathrm{E}-15$ & & & & & $8.85 \mathrm{E}-13$ \\
\hline 5 & & $1.51 \mathrm{E}-10$ & - & $5.79 \mathrm{E}-11$ & $2.08 \mathrm{E}-11$ & $3.23 \mathrm{E}-13$ & & & & & $2.72 \mathrm{E}-11$ \\
\hline 6 & & & $2.39 \mathrm{E}-10$ & - & 2.98E-09 & $9.83 \mathrm{E}-11$ & & & & & $1.78 \mathrm{E}-09$ \\
\hline 7 & & & & & - & $9.66 \mathrm{E}-10$ & & & & & $8.25 \mathrm{E}-09$ \\
\hline 8 & & & 3 & & & - & $3.01 \mathrm{E}-15$ & & & & \\
\hline 9 & E-14 & -13 & E-12 & E-10 & E-10 & $01 \mathrm{E}-15$ & - & $6.53 \mathrm{E}-11$ & $5 \mathrm{E}-11$ & 3E-11 & $3.01 \mathrm{E}-10$ \\
\hline 10 & 4E-14 & $39 \mathrm{E}-13$ & $87 \mathrm{E}-12$ & E-10 & E-10 & $1.54 \mathrm{E}-14$ & $2.02 \mathrm{E}-10$ & - & $7.16 \mathrm{E}-11$ & $3.29 \mathrm{E}-11$ & $7.75 \mathrm{E}-10$ \\
\hline 11 & $61 \mathrm{E}-15$ & $26 \mathrm{E}-13$ & $.06 \mathrm{E}-12$ & $1 \mathrm{E}-10$ & $1.51 \mathrm{E}-10$ & 4.43E-15 & $5.04 \mathrm{E}-11$ & $4.76 \mathrm{E}-11$ & - & $1.60 \mathrm{E}-11$ & $2.24 \mathrm{E}-10$ \\
\hline 12 & $31 \mathrm{E}-15$ & $40 \mathrm{E}-14$ & $.45 \mathrm{E}-13$ & $1 \mathrm{E}-11$ & 3.44E-11 & $8.45 \mathrm{E}-16$ & $9.13 \mathrm{E}-12$ & 7.91E-12 & $5.80 \mathrm{E}-1$ & - & $3.52 \mathrm{E}-11$ \\
\hline$i$ & 2.04E-11 & $2.08 \mathrm{E}-10$ & 2.77E-09 & 4.40E-08 & 4.93E-08 & $8.14 \mathrm{E}-13$ & 9.02E-09 & 7.52E-09 & 3.27E-09 & 1.42E-09 & - \\
\hline \multicolumn{12}{|c|}{$T=10000 \mathrm{~K}$} \\
\hline 3 & - & $3.50 \mathrm{E}-11$ & & & & & & & & & \\
\hline 4 & & - & $1.04 \mathrm{E}-10$ & & & & & & & & \\
\hline 5 & $1.31 \mathrm{E}-11$ & $.24 \mathrm{E}-10$ & - & $8.42 \mathrm{E}-11$ & $3.10 \mathrm{E}-11$ & $3.64 \mathrm{E}-13$ & $1.76 \mathrm{E}-12$ & $1.35 \mathrm{E}-12$ & $6.06 \mathrm{E}-13$ & $3.38 \mathrm{E}-13$ & $5.88 \mathrm{E}-11$ \\
\hline 6 & $1.06 \mathrm{E}-12$ & $.32 \mathrm{E}-11$ & $2.62 \mathrm{E}-10$ & - & 3.02E-09 & $8.46 \mathrm{E}-11$ & $1.60 \mathrm{E}-10$ & $1.17 \mathrm{E}-10$ & $5.90 \mathrm{E}-11$ & 3.64E-11 & $2.65 \mathrm{E}-09$ \\
\hline 7 & 51E-12 & $1.99 \mathrm{E}-11$ & $3.74 \mathrm{E}-10$ & $1.17 \mathrm{E}-08$ & - & $7.85 \mathrm{E}-10$ & $9.36 \mathrm{E}-10$ & $6.53 \mathrm{E}-10$ & $3.38 \mathrm{E}-10$ & $2.09 \mathrm{E}-10$ & $1.13 \mathrm{E}-08$ \\
\hline 8 & $03 \mathrm{E}-16$ & $6.52 \mathrm{E}-15$ & $3.00 \mathrm{E}-13$ & 2.24E-11 & $5.37 \mathrm{E}-11$ & - & $2.59 \mathrm{E}-15$ & $1.64 \mathrm{E}-15$ & $6.94 \mathrm{E}-16$ & $3.60 \mathrm{E}-16$ & $1.25 \mathrm{E}-14$ \\
\hline 9 & $8 \mathrm{E}-14$ & & $.75 \mathrm{E}-12$ & $1.10 \mathrm{E}-10$ & $1.66 \mathrm{E}-10$ & $6.72 \mathrm{E}-15$ & - & $5.53 \mathrm{E}-11$ & $2.04 \mathrm{E}-11$ & $1.01 \mathrm{E}-11$ & $3.62 \mathrm{E}-10$ \\
\hline 10 & & & $.87 \mathrm{E}-12$ & & $3.56 \mathrm{E}-10$ & $1.31 \mathrm{E}-14$ & $1.70 \mathrm{E}-10$ & - & $5.90 \mathrm{E}-11$ & $2.67 \mathrm{E}-11$ & $9.28 \mathrm{E}-10$ \\
\hline 11 & $38 \mathrm{E}-15$ & $.19 \mathrm{E}-13$ & $.59 \mathrm{E}-12$ & $.10 \mathrm{E}-11$ & $1.20 \mathrm{E}-10$ & $3.60 \mathrm{E}-15$ & $4.08 \mathrm{E}-11$ & $3.84 \mathrm{E}-11$ & - & $1.28 \mathrm{E}-11$ & $2.63 \mathrm{E}-10$ \\
\hline 12 & & $.09 \mathrm{E}-14$ & $.14 \mathrm{E}-13$ & & 2.64E-11 & $6.65 \mathrm{E}-16$ & $7.16 \mathrm{E}-12$ & $6.19 \mathrm{E}-12$ & $4.56 \mathrm{E}-12$ & - & $4.08 \mathrm{E}-11$ \\
\hline$i$ & $2.69 \mathrm{E}-11$ & $2.46 \mathrm{E}-10$ & $2.96 \mathrm{E}-09$ & 4.29E-08 & 4.72E-08 & $7.66 \mathrm{E}-13$ & 8.54E-09 & 7.12E-09 & $3.10 \mathrm{E}-09$ & $1.35 \mathrm{E}-09$ & 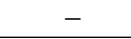 \\
\hline
\end{tabular}

Notes. The labels for the initial and the final states are listed in Table 1. 